\title{
Awards Presented at the 41st Annual Meeting of the BEHAVIOR GENETICS ASSOCIATION
}

\author{
Thursday, June 9th, Hotel Viking, Newport, RI, USA
}

(C) Springer Science+Business Media, LLC 2011

The Association's annual awards were presented at the Banquet, held at the Hotel Viking, Newport, RI, USA. President-Elect Michael Pogue-Geile served as the master of ceremonies.

The 34th Annual Thompson Award for the best presentation by an associate member was presented by Timothy Bates to two oral presentations: Roseann Peterson, for 'On the association of common and rare variation influencing body mass index: a combined Single Nucleotide Polymorphism and Copy Number Variation analysis' and Claire Coyne for 'Like mother, like daughter?: a quasi-experimental study of the intergenerational transmission of teenage childbearing.'

The eighth annual Fuller and Scott Award for outstanding early career contributions to the field was presented by Past President Dorret Boomsma to Brian D'Onofrio and Sarah Medland.

The eleventh annual Fulker Award for the outstanding paper in Behavior Genetics during the past year was presented by John Hewitt, Editor of Behavior Genetics, to Matthew Keller, Sarah Medland and Laramie Duncan for "Are extended twin family designs worth the trouble? A comparison of the bias, precision, and accuracy of parameters estimated in four twin family models."

Nancy Pedersen presented the James Shields Award for excellence in twin research to Paul Lichtenstein.

Past-President Michael Neale presented the 34th annual Dobzhansky Award for outstanding lifetime contributions to the field of behavior genetics to Matthew McGue.

Respectfully Submitted,

Arpana Agrawal

Secretary, Behavior Genetics Association

Michael Neale

Past President, Chair of the BGA Awards Committee 